\title{
Transformation of Private Enterprise Internationalization Model
}

\section{in Wenzhou}

\author{
Shouchao $\mathrm{He}$ \\ Wenzhou University, Wenzhou 325035, China \\ E-mail: wzuni@wzu.edu.cn \\ This article is supported by WENZHOU MUNICIPAL SCI-TECH BUREAU, PROJECT (No. R20090067)
}

\begin{abstract}
Due to the financial crisis, a series of changes have been brought to global trading environment. Compared with internal-oriented companies, private enterprises in Wenzhou, most of which are in export-oriented internationalization model, suffer more in the financial crisis. The traditional internationalization model of these enterprises in Wenzhou is forced by the complicated and volatile foreign trade environment to have their model changed; therefore, this thesis will analyze financial crisis' impacts on traditional operation model of such enterprises and present a way for transformation.
\end{abstract}

Keywords: Transformation, Private enterprises, Internationalization model, Financial Crisis

\section{Introduction}

Global economy suffers a lot in financial crisis; for china, even though Chinese financial institutions are not greatly influenced, arrears of payments, recession of external needs, decrease of orders' number and aggravating trade frictions have been emerging as the result of Chinese export enterprises' being serious affected by economic decline in the USA and Europe, which was caused by the financial crisis. As the earliest and fastest developing area with export-oriented economy, Wenzhou suffers the worst. Currently, great uncertainty still exists in global economy in spite of visible signs its recovery. In such a complicated and volatile foreign trade environment, private enterprises in Wenzhou need to find the way to extricate them from troubles, adapt to new marketing circumstances, review disadvantages of its internationalization model and respond to challenges with active measures.

\section{The financial crisis has brought new changes to Chinese foreign trade environment}

\subsection{Global economic recession caused by the financial crisis is reducing number of orders}

Financial crisis in the USA turns back and slackens the entire economy of the world. According to the estimation of the World Bank, growth rate of global economy in 2009 will be reduced from $2.5 \%$ in 2008 to $0.9 \%$, thus Chinese merchandise exports will be restrained by obvious economic slowdown of developed countries headed by the USA. It estimates that one percent reduction of the USA GDP's growth rate will result in 4.75 percents reduction of Chinese export growth rate; it also estimates that one percent reduction of economic growth rate in the EU will result in 15 percent reduction of electronic products export from China, as well as 5 percent reduction of Chinese textiles and apparels' growth rate. Based on proclamation of IMF, issued on June 15th, the USA GDP in 2009 will drop $2.5 \%$. With decreasing export orders' number and amount, Chinese exports are serious constrained by depressing overseas demand, which was caused by low consumption in the USA and EU. Furthermore, many Chinese export enterprises are facing the problems of doubtful orders payments, insufficient current funds, and impossible continuation. In the words of Yi Xiaozhun, deputy head of Ministry of Commerce of the People's Republic of China: Chinese export in the first 6 months of 2009 has fallen $21.7 \%$ compared with that in 2008. Even if overseas demand for Chinese exports will rise following recovery in world's major economies, great uncertainty still exists in quickly return of global economy.

\subsection{The financial crisis has aggravated protectionist measures for protection in local industries and markets}

Due to the financial crisis, protectionist policies regain preference with wide speculations in developed countries to protect employment against competition from lower-cost countries. Even worse, unbalance trading between regions and trade conflicts has been worsened by long-term trade surplus in China, and accordingly, administrations in countries like Japan, EU, Australia and the USA are tending to apply protectionist policies. To be more specific, attempt of Aluminum Corporation of China to become shareholder of Rio Tinto was rejected by the latter party unilaterally; 1.8 billion dollars offer from China Minmetals Corporation to OZ Minerals was 
vetoed by the Australian government; the clause to Buy American Products was listed in American Recovery and Reinvestment Act of 2009, passed by the Congress in February, 2009, the EU announced a policy to apply the $85 \%$ punitive duty on screws and bolts produced in China, and more than 200 Chinese enterprises, spare parts suppliers for EU automobiles, household utensils and machineries, will be affected by this rule. In brief, details mentioned above have manifested awareness of New Protectionism in developed countries. The New Protectionism shows more complicated, concealed or discriminatory features and contains new content like health, security, and environmental protection, thus takes dynamic trend towards multilateral trade rules. This policy has been frequently applied in the form of laws, rules and administrative decrees; moreover, it has spread from merchandise trade to employment and finance.

\subsection{Risks related to $R M B$ exchange rate have increased with vagueness of its float}

Current exchange rate of RMB against US dollar has been rising since reform of RMB exchange rate in 2005, and in consequence, Chinese export enterprises, especially small and medium ones, have been facing severe pressure to survive. Though there was slow appreciation of RMB against US dollar, the rapid appreciation of US dollar, manifested in more than $20 \%$ appreciation towards other currencies like Euro, Great Britain Pound, and Australia Dollar, plus stable exchange between RMB and US dollar, greatly restrained appreciation. In the corresponding period, the Vietnamese Dong, the Indian Rupee, Korean Won and currencies of other economic entities have encountered a big devaluation against U.S. dollar and the import demand of Europe and America has been diverted to Vietnam and other economic entities significantly. Seemingly, RMB exchange rate shows little fluctuations, however, U.S. dollar has actually presented a great appreciation against other currencies, which consequently caused a big pressure to the exportation of China. Moreover, owing to the issues of raw material price, labor force, financing environment and so on in itself, the competitiveness and risk resistance capacity of the export enterprises in China have been weakened to a certain extent.

\subsection{Great fluctuations of energy prices have increased uncertainty of enterprises' manufacturing costs}

Chinese economy has been greatly affected by great fluctuations of energy prices, especially the price of oil. It took only 18 months for international oil price to rise from 60 dollars per barrel in January, 2007 to 147 dollars per barrel, and 4 months for it to fall from its maximum to original 60 dollars per barrel, the speed and range of which are really unprecedented. When oil price was rising, price of other forms of energy, like coal; raw materials, like steel, aluminum, industrial chemicals; the base material for apparel production or textile, mechanical and materials for electrical or industrial products have also been greatly raised. Due to considerable rising of materials and primary products, plus Chinese's lack of pricing power in export products, export enterprises have to confront the difficulties of cost rising and falling profit rate. Prices of materials and energy were collapsing after the financial crisis, yet some export enterprises have hoarded up great amount of materials, thus lots of small or medium-size enterprises have to cut jobs, stop work or even collapse with crash of finished products' prices. At the same time, great fluctuations of energy prices have increased uncertainty of enterprises' manufacturing costs, increased risks in production and export, and affected confidence of entrepreneurs.

\subsection{The difficulty for pricing of export products has increased with constant adjustment of export rebate rates}

Since August of 2008, Ministry of Finance of People's Republic of China and State of Administration of Taxation has adjusted export rebate rates for 7 times to support development of foreign trade industry. The nearest adjustment in June, 2009, has focused on enforcement of different export rebate rates to different products and promotion of exports in superior products, labor-intensive products, and high-tech products by increasing support. Though improving export rebate rates could lower export costs of enterprises, roll back tension in foreign trade enterprises' funds chain, reinvent advantages of products' price and improve competitive power of Chinese products. Nonetheless, the effects of export rebate rates are limited, and the government will readjust export rebate rates to increase fiscal revenue in economic recovery period. What's more, most Chinese labor-intensive enterprises are making money mainly by OEM, and the lack of pricing power or brand advantages often made foreign trade enterprises to pay foreign importers parts of profits in export rebate to capture market in actual trading process. Therefore, the key factor still lays in accelerating upgrading of enterprise internationalization and foreign trade growth by industrial structures' adjustment, in the long term view.

\subsection{GSP treatment to Chinese products has been reduced by adoption of a new GSP scheme regulation in EU}

According to the new GSP scheme regulation in EU, which would be in practice from January 1th, 2009, most products made in mainland China that wouldn't subject to current preferential policy are still listed in the No. 1 attachment of the regulation's amendment. Consequently, these particular concerned mainland China-made products, like toys, textiles, shoes, furniture, lamps, jewelry, artificial jewels, electrical equipments, and watches, 
will not be subject to preferential policy anymore. Based on abolishment regulations for GSP, any country with serious or regular violation of international conventions and standards will be kicked out of Lists of Benefit Countries of GSP by the Council. The European Commission will also disqualify certain products when there has been enough competitiveness and calls for no preference of GSP to increase its export to the EU. Under the terms of this regulation, tariff preference for certain country will be cancelled when average value of its export products to the EU has exceeded $15 \%$ of similar products' total value, which was counted by all values of such products from all benefit countries, and lasts for more than 3 years. Enterprises with different value-added products take different sustainability to the new GSP regulation, while enterprises with high value-added products suffers little, enterprises with low value-added products, which have been trapped by intense competition in the post-quota era, will be put in a pretty fix for its low profits diminished by additional export tariff.

\section{Impacts of the financial crisis to traditional internationalization model of private enterprises in Wenzhou}

The definition for enterprises' international management refers to the process of enterprises' active involving in international division of labor to evolve from domestic management to global operation. This concept focuses on the two-way process to both domestic and foreign orientations. Enterprises in the district of Suzhou are employing "Bring In" featured domestic-oriented model, yet enterprises in the district of Wenzhou are applying "Going Out" featured foreign-oriented model. Thus, foreign-oriented internationalization model and features of private enterprises in Wenzhou made them suffer more impacts from financial crisis than enterprises in domestic-oriented model.

\subsection{Features of traditional internalization model applied by private enterprises in Wenzhou}

Viewed from the point of internationalized process of private enterprises in Wenzhou, it has been on a progressive internationalized process which was similar to step-by-step process of Learning by Doing. With accelerating process of internationalization, private enterprises in Wenzhou began to jump from step-by-step processing to a radical one, which was displayed by sharp increase of foreign trade, fast expansion in overseas investment scale, diversification of overseas markets and popularity of international spirits. For motivation of internalization, main targets for these enterprises' internationalization are to seek overseas market, access overseas resources and earn enormous profits, which were only focused on "Going Out". For their forms, these dispersive small or medium-sized enterprises carry out transnational operations for respective interests and are short of group fighting spirits and development of trunked brand effects. For proportions in exports and imports, exports have exceeded imports a lot with ratio of export's total amount against imports' to more than 4:1. Exports of foreign trade in first 6 months of 2009 were 4.816 billion dollars, and 1.143 billion in imports. Forms of foreign trade are mostly in ordinary trade, plus little processing trade, which has significant differences with trade in Jiangsu and Guangzhou. Enterprises in the two districts mentioned above focus on self-owned brands and independent innovation and depends less on OEM. Features for internationalization mode of private enterprises in Wenzhou are listed in chart1.

\subsection{Impacts of the financial crisis on traditional internationalization model of private enterprises in Wenzhou}

Private enterprises in Wenzhou have been greatly affected in severely changed foreign trade environment which was caused by impacts of the financial crisis. As Zhou Dewen, the President for Wenzhou Association of Small and Medium Enterprises, said on November 16th, 2008; about 20\% of such enterprises in this city were in the status of wholly or partly shut down and $8 \%$ of such enterprises has been confirmed as insolvency by investigation of Economic \& Trade Bureau of Wenzhou. Even if viewed in the point of multinational operation, exports-oriented model in Wenzhou, for example the foreign-oriented internationalization model, was also seriously affected. Exports of Wenzhou in 2008 shrunk greatly, and a negative growth has been detected in exports in the first month in 2008. The amount of general trade, has also dropped by $13.79 \%$. Details are listed in Chart 2.

Main reasons for rapid decrease in Wenzhou's exports lay in disadvantages of its traditional internationalization model. First of all, the foreign-oriented internationalization model focuses on export and belongs to foreign-investment introducing \& single export, which cares little about overseas investment or consumer imports and has resulted in grand trade surplus. Such model is unsustainable and no new open doors are available when foreign demands were reducing. Secondly, its main motivation focuses on developing overseas markets, which are vulnerable to impacts of regional protectionism; hence these enterprises were quite passive when facing the new trade barrier from awareness of protectionism. Thirdly, such enterprises are mainly labor-intensive industries, and they have lost their traditional competitive advantages of cheap labors and 
resources when the Law of the People's Republic of China on Employment Contracts has been recently issued, and when facing significant fluctuations of international energy prices. Fourthly, its forms are mainly in dispersal small and middle-size enterprises, thus conflicts between reducing foreign demands and over-production are also generated by overlapping investments, serious cut-throat competition and losing of markets. Fifthly, their target markets mainly depend on the USA and EU with more than $20 \%$ ratio of its exports to these districts, and thus they care little about emerging markets, which make the shrinking of exports inevitable when occident has to turn to policies for local employment and market to deal with impacts of the financial crisis. Sixthly, such enterprises have been adhering to the low-cost competitive strategies to export great amount of its products to international markets with low prices, low costs and new styles. Barriers would be set for products made in Wenzhou with excuses like laws or regulations, safety or security, cultural reasons, environmental protection and patents, which were applied by local governments to assist competition of local enterprises with similar products. Seventhly, the appreciation trend of RMB has reduced more taxes of OEM than general trading for enterprises. Since general trading enjoys more ability against appreciation of RMB than OEM, profit margin of general trading dropped more than that of OEM.

\section{The transformation of internationalization model of private enterprises in Wenzhou to adapt to the financial crisis}

Since internationalization progress of private enterprises in Wenzhou started early, evident effectiveness of enterprises' internationalization has been emerged. Internationalization of such enterprises was great challenged by shrinking global economic environment in the financial crisis. The keys for those enterprises to get rid of morass and be marginalization in international trade system lay in reflection of traditional internationalization's disadvantages, break system tariff or thinking inertias, and reform inappropriate progress in new circumstances. The transformation mode for these enterprises, based on their actual states, could be summed up in Chart 1 . Generally speaking, the progress for transformation of these enterprises' internationalization still follows the principle of Step-by-Step. The foreign-oriented focusing model will be changed to domestic-oriented internalization gradually, and a Spillover Effect from joint venture is expectable with foreign capital brought by joint venture. By enlarging shares of import trade, decreasing trade tariff, improving technological content and added value, foreign capital brought advantage technology, management, system, opinions, so international marketing channels could be obtained, and conditioning factors to its development could be broken through, reforms to developing model could be achieved.

\subsection{To evolve from "Going Out" to "Bring In" and promote positive interaction of the two policies}

The progress of internationalization of private enterprises in Wenzhou was a market expansion based on its comparative advantages; it was mainly in labor-intensive industries and depended on quantitative expansion or price competition. Since it belongs to inter-industries trading, rather than intra-industries trading, it was disadvantaged in trade profits distribution. Even if a new way of Foreign Industries Introducing by Private Enterprises, Merging of Foreign Industries and Private Enterprises has been presented by government of Wenzhou, its effects were not obvious without substantial transformation in constitutions of foreign trade in Wenzhou. Private enterprises in Wenzhou far behind Suzhou have turned to be important factors to condition its structure's upgrading and transformation of its industries. Mergers were politics-colored with the global financial crisis's serious impacts on global economy. Chinese investment policy was doubted with Ministry of Commerce of the People's Republic of China's prohibition on Coca-Cola Company's acquisition of China Huiyuan Juice Group Limited, and China was considered to have applied protectionism. Yet the failure of this acquisition should be resulted from violation of Chinese Law on Anti-Monopoly. Under the background of the financial crisis, development of the private enterprises in Wenzhou should still follow the principle of" introduction of foreign source based on private enterprises, ally of private enterprise and foreign source" to move forward, private enterprises shall achieve industrial upgrade, make domestic economy and the international economy complement each other and achieve win-win by introducing international advanced management, technology, brand, reform themselves and improve technical standards, When practicing the policy of "bring in", the private enterprises in Wenzhou should also speed up the strategy of "going out", private-owned capital in Wenzhou is abundant, while the financial crisis provides a great opportunity for the private enterprises to conduct overseas acquisition, the private enterprises in Wenzhou should seize the opportunity to develop international and regional investment and acquisition with great potential, they should take advantage of original resource, brand and sales network to expand their market share. It is high recommended to shift process production to less developed countries with lower labor-cost if they plan to invest and build factories overseas, such as Africa, Latin America and so on, then re-export to EU, in this way it is conducive to continue using the GSP to expand the EU market. 


\subsection{As an internationalization carrier, work cluster plays a competitive advantage in international operation in} the form of participation of cluster

Wenzhou's internationalization road depends on the very important factor--overseas network, overseas immigrants from Wenzhou bring a large number of orders to private enterprises in Wenzhou, leading enterprises in Wenzhou and their products to the whole world. Wenzhou's unique network of abroad relationship provides enterprises in Wenzhou with access to international market information and business opportunities, international experience \& knowledge and accumulation of international reputation capital, and it also makes enterprises prefer outward international operations like export trade and foreign investment. However, private enterprises in Wenzhou are mainly in the form of individual companies, or their products are mainly oriented to overseas markets, it will not a big problem with this form in great demand, but they suffer misfortune due to weak strength when it comes across to financial crisis, it is one example that Wenzhou Overseas Mall shows inadequate force in boosting export. According to statistical data from Wenzhou Municipal Foreign Economic and Trade Bureau, merchandise export of Wenzhou boosted by overseas agencies reached 710 million U.S. dollars in 2006, while the value in 2009 decreased to 550 billion US dollars. However, Wenzhou businessmen decisively act "alliance" countermeasures with their unique shrewd minds. Eighteen foreign trade garment companies, including Wenzhou Allta Garment Co., Ltd, WELLHOPA finery Co., Ltd, MXISI clothes Co., Ltd, Zhida garments, allied together and built Wenzhou Xuezhimeng Group, in fact, the group is an international apparel industrial park, these companies will joint to set up independent brand, market expansion, product development and enter the international market after the project is completed. As a matter of fact, the form is an enterprise cluster, by means of unified foreign-oriented promotion, standardized quality standard, identified specific technology, promotion of their common brand, share of cluster reputation and "cluster effect". The enterprise cluster can seek a differential advantage in the internationalization process, which is very difficult for the single small-sized and medium-sized enterprises to grip; Initial capital which enterprises inside the cluster require to develop export-oriented economy will be far less than that enterprise outside the cluster require, in this way the enterprise cluster can help resolve the financing difficulty that private enterprises face. Therefore, under the financial crisis, private enterprises in Wenzhou still use allied mode to realize sharing advantage resources through enterprise cluster, and large-sized enterprises push small-sized enterprises to achieve common development.

\subsection{Increase proportion of the processing trade, shift from participation in "out-sourced" line to guide line of "out-sourced"}

Gap between proportions of ordinary trade and processing trade in Wenzhou private enterprises export trade structure is too obvious, processing trade has been soft spot of Wenzhou's foreign trade, and it is in unfavorable position under background of appreciation of the RMB. Technological content and added value of ordinary trade merchandise is relatively low, while footwear, clothing, leather and other labor-intensive industries will gradually lose their competitive advantages. Processing trade is one of the most effective ways to combine local throughput advantage with low-cost and technology advantage of developed countries, and there is a trend that international division of labor shifts from labor division mainly with inter-industry to labor division within the industry. Private enterprises in Wenzhou should take the financial crisis as a turning point to adjust their trade structures, emphasize on attracting FDI, develop re-export processing trade, and join in international industrial chain continually, they should convert from pushing upgrade of the industry to boost upgrade of the industrial chain, meet international requirements and standards of the industry quickly in aspects of production technology, processing, business management, staff quality, quality control, productivity, etc., and narrow the gap between us and the advanced countries in a full range. As a matter of fact, internationalization of private enterprises started with participation in "out-sourced" of foreign companies, in which internationalization of Wanxiang Group can be viewed as a most typical model, its internationalization conforms to approach from low-end contractor of out-sourced to the route that takes initiative position instead of passive position to achieve international operation. Obviously the shift from participation in "out-sourced" to leading "out-sourced" to realize international expansion is a feasible approach of internationalization of private enterprises in Wenzhou.

\subsection{Strengthen original, integrated and digestion innovation, take advantage of technology to break trade barrier}

Products exported by private enterprises in Wenzhou are mostly low value-added, labor-intensive, they maintain a very low price level, which lead to a larger volume of export and so-called "cost-competitiveness". When it comes to the global financial crisis, single processing or primary production enterprise with labor-intensive, low-technology in Wenzhou will be inevitably impacted, while impact is relatively slight on other high-tech mechanical and electrical products. Innovative model enterprises in Wenzhou, such as Chint, Huafon, SEMIR, Wenzhou Huarun Electrical Machinery Co., Ltd, have emerged in the past few years, a large number of 
promising small-sized and medium-sized enterprises with innovative technology, which develop high-end products and establish R \& D centers, and these enterprises not only have vitality in technological innovation but also conduct constant reform on management, marketing, systemic mechanism and innovation, they show strong life force in financial crisis. Take Wenzhou Huarun Electrical Machinery Co., Ltd for example, one in ten of over 700 employees in the company is responsible for technical research and development, $5 \%-10 \%$ of the company income is put into technical innovation. Surrounded by depreciation of the U.S. dollar, world economic recession and financial crisis across the world, the company gross industrial output was 210 million Yuan, increased by $16 \%$ in 2007, and sales revenue reached 180 million Yuan, grew by $13 \%$ when compared with last year, revenue and tax was up to 6,000 million, increased by $12 \%$ in 2007 , and won a patent infringement case in respond to lawsuit filed by TISAS Co., Ltd. Under current international background where the new trade protectionism rages, the key for enterprises to break technical barriers depends on their ability to obtain intellectual property rights. Enterprises should learn experiences from successful ones and take the financial crisis as an opportunity to accelerate scientific and technological innovation to enhance independent innovation capability, speed up industrial restructuring and upgrade through original innovation and innovation of integration and digestion, The enterprises should set up a variety of technical centers and research institutions, increase investment in technological development, strengthen independent innovation capability; they should conduct independent R \& $\mathrm{D}$, introduction, digestion, absorption and re-innovation with advanced technology equipments and key technologies, strive to form independent intellectual property rights and core technologies; and the enterprises should increase investment force to upgrade and innovate their technologies, which include strengthening vocational and technical training for employees and quality training. These enterprises should create opportunities to gradually build their own technology and technique s R \& D teams, constantly develop new products, exploit new markets and improve corporate brand management capacity.

\subsection{Implement differentiated brand strategy to promote international operation of brands}

Brand value is the reflection of the brand competitiveness in international market. Brand positioning of localization is a mark of internationalization success. Private enterprises in Wenzhou have created excellent national brands like "Chint", "Delixi", "Kangnai" and "Red Dragonfly", but many Wenzhou private enterprises' understanding of brand is amiss, their minds are still lingering on the phase making products, they still view excellent quality, low price, fashionable style as the whole of the brand, when compared to high-profile Wenzhou brand, reputation of private enterprise's brand in Wenzhou is still very low. Compared to the international brands, brand value of private enterprises in Wenzhou is not high. In times of diversified customer demands and the more and more similar product quality, only product quality, technology and other factors can't form a lasting competitive strength. It is the key to differentiate positions of products, find a unique competitive advantage to increase brand value. Perceived value on some private enterprises in Wenzhou became very weak due to impact of global economic recession. On the contrary, some mature brands with great quality and value can benefit from this economic recession. Therefore, in an international environment of economic crisis, the priority of an enterprise should be to develop a brand recognized by the consumers. Wenzhou private enterprises should realize the shift from brand quantity to brand quality, from product brand to brand of the enterprise, from industry brand to the regional (city) brand, from single brand to integrated brand, from tangible brand to intangible brand. Private enterprises in Wenzhou can use a variety of methods, such as joint business operation with foreign brands, incorporated acquisition and processing overseas to boost extension of their brands overseas and promote international operation of their brands. Meanwhile, local government should improve local laws and regulations regarding protection of the brand and the trademark to build a great legal environment on protection of the brand.

4.6 Gradually shift from the Europe and United States markets to international emerging markets, break the shackles of shrinking demand of well-developed countries

Impacted by the financial crisis, the distribution trend that Wenzhou export has always high concentrated on --the Europe and United States markets form tight restriction to strong growth in export trade in Wenzhou,, market demand of major developed countries from Europe and the United States shrink sharply, while thresholds of the developed countries are generally high, so are their standards. Under background of growing trade protectionism, export of private enterprises in Wenzhou have decreased substantially, take mechanical and electrical products for example, export of electromechanical products made in Wenzhou was 1.629 billion U.S. dollars from January to May, down $18.43 \%$ over the same period, but export the emerging markets showed promising development trend. From January to May, the amount of Wenzhou electromechanical products exported to Malaysia, Mexico, Liberia and Bangladesh was 62.66 million U.S. dollars, 31.77 million U.S. dollars, 14.78 million U.S. dollars and 11.57 million U.S. dollars respectively, with a respective year on year increase of $111.81,10.99 \%, 1205.9 \%$ and $58.17 \%$ percent. Under such circumstance, private enterprises in Wenzhou should actively develop new 
international markets to realize diversification of export markets, and relieve the pressure of slowdown in export to developed countries through increasing export to the ASEAN, the Middle East, Russia and Latin America. Products with competitive price and quality certainly will gain new growth points in these markets. More specifically, expansion on market diversification in Europe and North America markets should be deepened, Southeast Asian markets should be recovered and stabled, and xx Africa market shall be exploited actively, while Latin America, Russia and Eastern Europe markets should be expanded steadily. Since these emerging markets are not quite perfect, corresponding legal system is not complete, and credit risk is very high, foreign trade enterprises should be aware of all these adverse factors when they are seeking emerging markets. Resources of an individual enterprise are limited, while the international market is extremely tangled, national conditions of countries are vastly different., and response ability of the individual enterprise to risk is relatively weak, thus the government should adopt policies to eliminate worries of the export enterprises of the risk to export and difficult to get back their money. For example, in order to encourage foreign trade enterprises to expand export on emerging markets, Jiangsu took measures to boost export of ordinary trade export by credit guarantee, help enterprises enhance their international competitiveness, exploit new markets, and develop new customers and receive new orders. Therefore, Wenzhou municipal government can use the practice of the Jiangsu province.

\section{References}

He Shouchao. (2008). Discussion on transformation of enterprise internationalization in Wenzhou. Productivity research, 1 , pages $81-84$

$\mathrm{Lin} \mathrm{Li}$, and $\mathrm{Xu} \mathrm{Xu}$. (2008). Comparative Study on Internationalization Degree based on the Inward and Outward Regional Economy --- Take Wenzhou, Suzhou and the Quanzhou regions for example. International Trade Issues, (10): Page 57-61

Lu Tong, and Li Caoming. (2003). Internationalization of Private Enterprises in Wenzhou. World Economy, (5): Page 55-63

Ren Xiao. (2008). Internationalization Model of Private Enterprises in Wenzhou. International trade Issues, 8(10): Page 76-81

Tian Jianying. Analysis on Decision-Making Factors of Internationalization of Private Enterprise's Independent Brand --- Take Ningbo as example. Comparison on Economic and Social System, Page 163-166

Zhao Wei. (2009). Zhejiang Model A Multi- Transformation Model of Regional Economy - Three decades Transformation of Multi-Horizon. Zhejiang Social Sciences, (2): Page 22-31

Zheng Zhun, and Wang Guoshun. (2009). Analysis on Internationalization Growth Mechanism of the Enterprise on Network Resource - Take private international enterprise in Wenzhou as example, (2): Page 41-46

Zhu Huayou, and Zhou shuyun. (2009). Study on Development Strategy of Internationalization of Local Industry Cluster - take Yongkang hardware industry cluster as example. East China Economic Management, (2): Page 61-65 
Chart 1. Parallel table for fore and after transformation of private enterprises in Wenzhou's internationalization model

\begin{tabular}{|c|c|c|}
\hline Comparing latitude & before transformation & after transformation \\
\hline General features & foreign-oriented internationalization & $\begin{array}{l}\text { domestic market was still grabbed } \\
\text { when focus on foreign trade }\end{array}$ \\
\hline Speed & step-by-step & Step-by-step \\
\hline Motivation & $\begin{array}{l}\text { Overcapacity, business development } \\
\text { intensify domestic competition } \\
\text { shrinking domestic market }\end{array}$ & $\begin{array}{l}\text { technology obtainment, internationalization } \\
\text { cooperation, global strategy }\end{array}$ \\
\hline Goal & Going out & combination of Going out and Bring in \\
\hline Forms of enterprises & dispersive enterprises with products & trunked enterprises with industries \\
\hline $\begin{array}{l}\text { Constitutions of exports and } \\
\text { imports }\end{array}$ & exports weights more than imports & equal in exports and imports \\
\hline Forms of foreign trade & mainly with general trade & with increasing gravity of processing trade \\
\hline Goal market & mainly for USA and EU market & USA, EU and emerging countries \\
\hline Industrial characters & labor-intensive industries & knowledge technology intensive industries \\
\hline Entry model & $\begin{array}{l}\text { overseas trade, OEM and international } \\
\text { cooperation }\end{array}$ & $\begin{array}{c}\text { Mergers, overseas investments and bases } \\
\text { establishing }\end{array}$ \\
\hline Business strategy & costs leadership & diversified brands \\
\hline Comparative advantages & low price, new models, and overseas network & high-tech and high added value \\
\hline
\end{tabular}

Chart 2. Parallel table for foreign trade of Wenzhou fore and after of the financial crisis

\begin{tabular}{c|c|c|c|c|c|c}
\hline Indexes & In 2007 & $\begin{array}{c}\text { Growth } \\
\text { compared to } \\
\text { last year (\%) }\end{array}$ & In 2008 & $\begin{array}{c}\text { Growth } \\
\text { compared to } \\
\text { last year (\%) }\end{array}$ & $\begin{array}{c}\text { the first 5 } \\
\text { months of } \\
2009\end{array}$ & $\begin{array}{c}\text { growth compared } \\
\text { to corresponding } \\
\text { period of last year } \\
(\%)\end{array}$ \\
\hline Gross exports & 101.48 & 25.6 & 119.04 & 17.3 & 38.53 & -12.67 \\
\hline General trade & 96.67 & 26.2 & 112.31 & 16.2 & 35.94 & -13.79 \\
\hline OEM & 4.79 & 14.2 & 6.69 & 39.8 & 2.59 & 0.6 \\
\hline
\end{tabular}

